\title{
Foodborne Diseases Related to the Consumption of Flesh Foods in Morocco (2010-2016)
}

\author{
Meryem Boukili $^{1^{*}}$, Fouzia Rhazi Filali ${ }^{1}$, Sanaa Benlarabi ${ }^{2}$, Rachid Hmimou ${ }^{2}$, Rachida Soulaymani-Bencheikh ${ }^{2,3}$ \\ and Majida Sefiani ${ }^{1}$ \\ ${ }^{1}$ Team of Microbiology and Health, Laboratory of Chemistry-Biology Applied to the Environment, Moulay Ismail University Faculty of Sciences, BP. \\ 1120, Zitoune, Meknes, Morocco \\ ${ }^{2}$ Moroccan Anti-Poison and Pharmacovigilance Center, Rabat, Morocco \\ ${ }^{3}$ Mohammed V University, Rabat, Morocco \\ *Corresponding author`s Email: m.boukili@edu.umi.ac.ma
}

\begin{abstract}
The current study aimed to determine the epidemiological profile of foodborne diseases associated with flesh foods during 2010-2016 in Morocco. A retrospective study of foodborne diseases caused by flesh foods recorded by the Moroccan anti-poison and pharmacovigilance center during 2010-2016. During this period, 2963 foodborne diseases related to flesh foods were declared to the center, in which $24.83 \%$ were registered in 2015 , and $20.75 \%$ in 2013. Diseases occurred mostly in urban areas $(67.06 \%)$. The major affected group's ages were adults (33.81\%) and children (14.44\%). The average patient's age was $25.09 \pm 15.37$ years. Male were the most vulnerable to infection $(54.80 \%)$ with a sex ratio (male / female) of 1.72 . The most incriminate flesh foods were respectively chicken (47.35\%), aquatic products (30.94\%) and red meat (16.57\%). The high incidence rate was related to chicken skewers (3.55 per 100000 people), while the high fatality rate was associated with giblets $(3.33 \%)$. Diseases due to the restauration outside home accounted for $58.15 \%$. The majority of cases were collective $(84.27 \%)$ and occurred significantly in spring $(18.49 \%)$ and summer $(14.51 \%)$. clinical symptoms were present in $67.19 \%$ of cases, mostly moderate $(81.77 \%)$ with four death cases corresponding to fatal condition. The high incidence rates were recorded in the regions of Sahara. Foodborne diseases are spreading progressively in Morocco, especially in summer and hot climates. The majority of these diseases are due to the consumption of contaminated flesh foods. Therefore, the responsible of food safety in Morocco must ensure the quality control of these foodstuffs.
\end{abstract}

Key words: Epidemiology, Foodborne diseases, Meat, Morocco

\section{INTRODUCTION}

The term flesh foods include all types of red meat, poultry, fish and their products (WCRF, 2018). They are among the major consumed foodstuffs around the world. During the period between 1961 and 2014, the global consumption of red meat and poultry has developed from 20 to 43kg/person/year (Ritchie et al., 2018). The Food and Agriculture Organization of the United Nations (FAO) has announced that the global consumption of fish and aquatic products has increased from 130 to 151.2 million tons during 2011-2016 and reach for the first time $20.1 \mathrm{~kg} /$ person/year in 2015 (FAO, 2018). In Morocco, according to the Ministry of Agriculture Fisheries Rural Development Water and Forests (MAPMDREF), the production of red meat destined for consumption has increase from 400000 to 550000 tons between the years 2008 and 2016, while the production of poultry has developed from 440000 to 620000 tons (MAPMDREF, 2017). Regarding the consumption of fish and aquatic products, it was doubled from 33717.2 to 66871.88 tons during 2000-2013 (FAO, 2013).

Because of their richness in micronutrients needed for the growth of pathogenic germs that are harmful to humans (WCRF, 2018; Nohr et al., 2007), flesh foods represent an important source of foodborne diseases worldwide (Heredia et al., 2018). Actually, poultry is considered as the first source of Salmonella (SfAM, 2014), while this germ is known as the major zoonotic bacterium responsible for death related to foodborne illnesses in the united states (Mead et al., 1999) and one of the public health problems worldwide (WHO, 2018). During 1980-2015, Salmonella was notified also as the second cause of foodborne outbreaks related to meat and its products globally (Omer et al., 2018), and one of pathogenic bacterium present mostly in fish and aquatic products (Novoslavskij et al., 2016). In USA, during 2009-2015, 4860 foodborne illnesses were associated with poultry, 2288 caused by fish and aquatic products, and 1984 by red meat (except the pork meat) (Dewey-Mattia et al., 2018). In France, the national institute for health surveillance has declared that red meat was the first responsible food for collective foodborne diseases during the years 2014-2015, followed by fish and poultry (Invs, 2014; Invs, 2015). In Morocco, according to the Moroccan Anti-Poison and Pharmacovigilance Center (MAPPC), from 17896 foodborne diseases cases declared during 1989-2008, fish and aquatic products were the 
second incriminated (20.3\%), followed by meat products (18.2\%) (MAPPC, 2010). Moreover, meat products were in the first position as the most incriminated foods in diseases cases in Morocco from 2013 to 2015 respectively with 40\%, $24 \%$ and $21.7 \%$, while fish and aquatic products were in the third position in $2014(14.7 \%)$ and 2015 (8.7\%) (MAPPC, 2013; MAPPC, 2014; MAPPC, 2015).

Taking into account this bibliographic overview, our study aims to highlight the epidemiological characteristics of foodborne diseases caused by flesh foods in Morocco, to describe the demographic and clinical characteristics of cases recorded by the MAPPC during 2010-2016.

\section{MATERIALS AND METHODS}

We proceeded to establish a retrospective descriptive epidemiological study of foodborne diseases associated with red meat, poultry and aquatic products registered by the MAPPC from 1 January 2010 to 31 December 2016 in Morocco. At this national institute, poisoning and diseases cases declared via the toxicological information service which was set up in 1980, are received and recorded in the declaration card which is completed by professionals in the health delegations and hospitals of Morocco. This center also records the statements from telephone records and /or monthly data of the cases declared by the provinces (MAPPC, 2009). The analysis of data is based on the characteristics study of affected population during the time interval of this study. For this reason, we took into account the age using. The INTOX classification method (WHO, 2000), sex and middle of residence. The second factor considered in this study concern the involved flesh food in disease case. Subsequently we assess the degree of severity, symptomatology and evolution of contracted diseases.

Poisoning Severity Score (PSS) was used to determine the severity of diseases in which the grade 0 corresponds to the absence of functional or physical sign, the grade 1 manifested by minor, transient and spontaneously regressing symptoms, the grade 2 is marked by persistent symptoms, the grade 3 shows severe or life-threatening symptoms, and the grade 4 corresponding to fatal poisoning (Persson et al., 1998).

The SPSS software (IBM SPSS Statistics, version 20) was used for data analyses, while the creation of maps was conducted using Microsoft excel 2016. The incidence and mortality rates were calculated based on the high commissioner for planning's data, and the variables were compared using the chi-square test with a significance level of $\mathrm{p}$ value $<0.05$.

\section{RESULTS}

The census of data records by the MAPPC during 2010-2016, showed a total of 2963 foodborne diseases cases related to flesh foods. The high frequencies of these diseases were registered in 2015 and 2013 respectively $736(24.83 \%)$ and $615(20.75 \%)$ cases. However, $1987(67.1 \%)$ cases have been detected in urban areas and $674(22.7 \%)$ in rural middle (Figure 1).

Regarding the responsible types of flesh foods for these diseases, the figure 2 shows that chicken represents a rate of $47.35 \%$ in which chicken skewers were the most incriminated $(83.89 \%)$, fish and aquatic products in the second position with $30.94 \%$, minced and red meat shows respectively $9.78 \%$ and $6.78 \%$, turkey corresponds to $3.78 \%$ in which turkey skewers were the most implicated $(54.46 \%$ ), giblet $1.02 \%$ and delicatessen $0.33 \%$. The most responsible foods for hospitalization were chicken and minced meat (35.08\%), while chicken, aquatic products, minced meat and giblet were incriminated in the four recorded death cases (Figure 2).

Concerning the characteristics of studied population, male was the most affected by foodborne diseases related to flesh foods with a percentage of $54.80 \%$ and a sex ratio (male /female) of 1.72 . The average patient's age was $25.09 \pm$ 15.37 years, while the age group most involved in this problem corresponds to adults with a percentage of $33.81 \%$, followed by that of children $14.44 \%$, and adolescents $6.54 \%$. With regard to the characteristics of recorded diseases, the majority of cases were collective representing approximately $84.27 \%$. The majority of declarations occurred first in spring with $18.49 \%$ and in summer with $14.51 \%$. Clinical symptoms are manifested in $67.19 \%$ of cases. The severity of diseases was mostly moderate rated at grade 2 in $81.77 \%$. Four recorded deaths corresponded to grade 4 with a $100 \%$ mortality rate. The application of chi-square test showed that $\mathrm{P}<0.001$ for all studied characteristics (Table 1).

The study of disease's severity due to flesh foods consumption according to seasons showed that the moderate grade (grade 2) was dominant during all seasons. Among 48.4\% of diseases cases recorded during the four seasons, $68.20 \%$ were declared during spring and summer, in which $92.53 \%$ are classified between moderate and severe severity. However, among 46,511\% of recorded hospitalization during the different seasons, $41.25 \%$ were detected in autumn, with two fatal cases were registered in autumn and summer seasons (Figure 3).

The high incidence of diseases was detected in 2015 (0.0215\% people) and $2013(0.0186 \%$ people $)$, while the high fatality rate was registered in $2012(0.36 \%)$ and $2014(0.21 \%)$. Concerning flesh foods, the high incidence of diseases was related to the consumption of chicken skewers $(0.0355 \%$ people) and aquatic products $(0.0205 \%$ people $)$, however 
the high fatality rate was related to giblets $(3.33 \%)$ with a hospitalization percentage of $43.33 \%$, and minced meat $(0.34 \%) .58 .15 \%$ of diseases were caused by consumption of food out of home (restaurants, educational institutions, public place, work), while $31.85 \%$ were related to the consumption of food at home (Table 2).

Regarding the distribution of these cases on the Moroccan territory, during 2010-2014 (before the territorial redrawing of 2015), the regions of Oriental and Meknes-Tafilalet (north- central of Morocco) have recorded the largest number of diseases respectively 527 and 360 cases, while the regions of Settat-Casablanca and Rabat-Sale-Kenitra (northeast of Morocco), have known the high frequency of diseases in 2015-2016 respectively 77 and 66 cases. In regard to the incidence rates of diseases, the high incidence registered during 2010-2014, was in the region of Oued ed DahabLagouira region situated in Sahara (1.78\% people) and oriental region (0.26\% people). However, in $2015-2016$, the highest incidence rate recorded the regions situated in Sahara two, Laayoune-Sakia El Hamra $(0.11 \%$ people $)$ and Guelmim- Oued Noun (4.35\% people) (Figure 4).

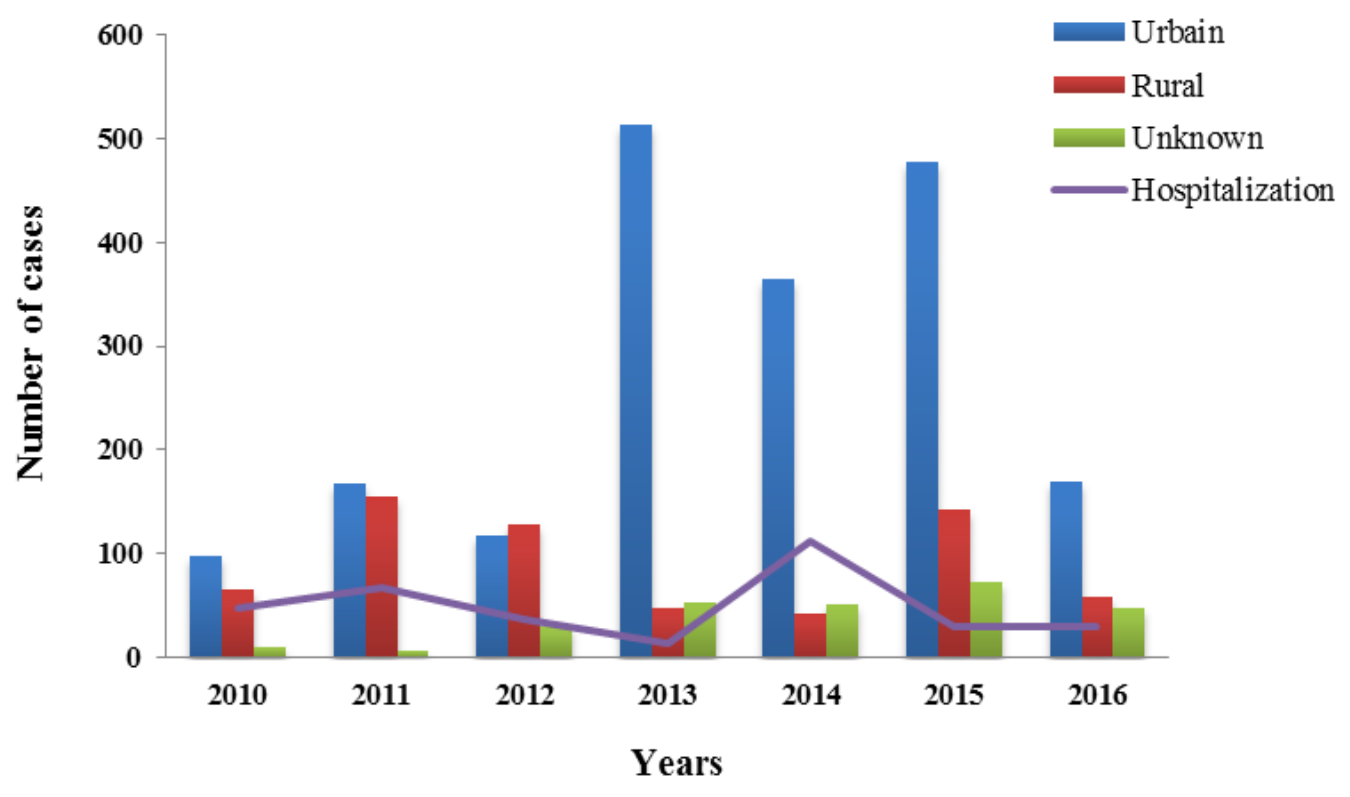

Figure 1. Foodborne diseases related to flesh foods according to years, middle of residence and hospitalization during 2010-2016 in Morocco.

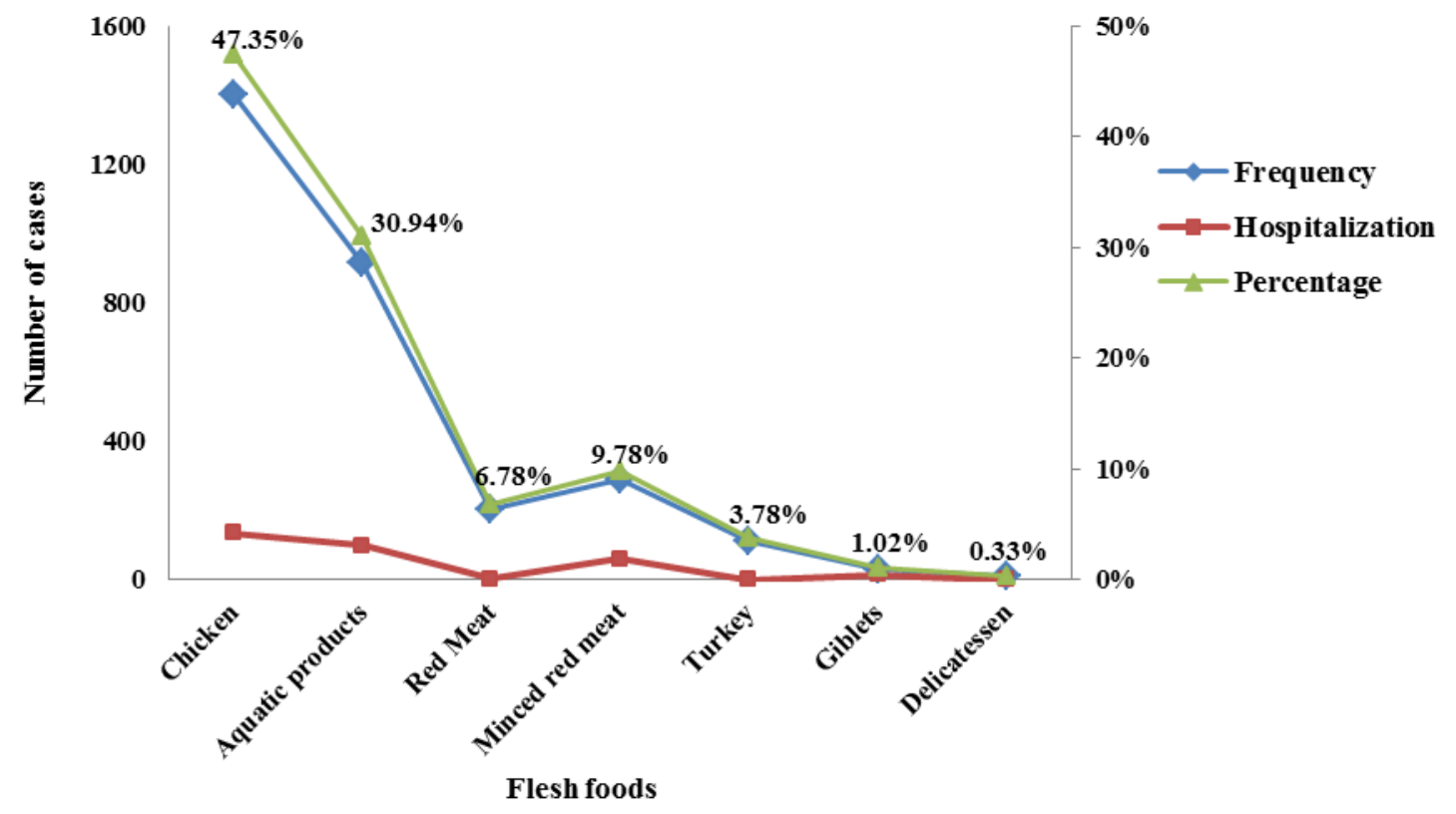

Figure 2. Distribution of diseases and hospitalization cases according to flesh foods types during 2010-2016 in Morocco 


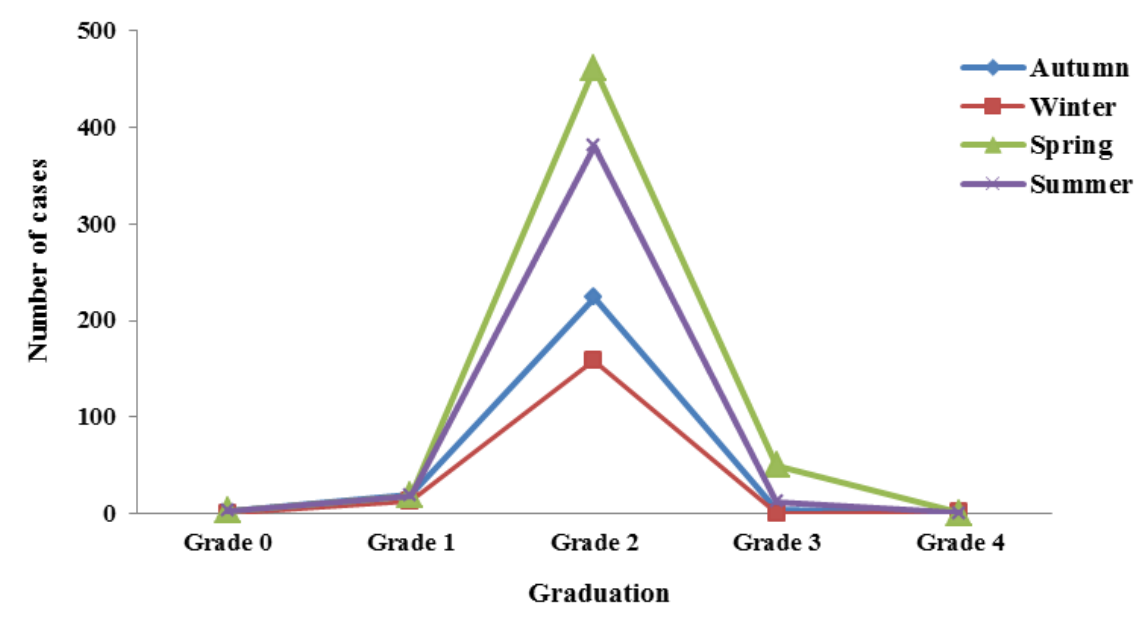

Figure 3. Severity of diseases according to the corresponding season during 2010-2016 in Morocco. Grade 0: Absence of symptoms. Grade 1: Symptoms slight. Grade 2: Prolonged Symptoms. Grade 3: Serious Symptoms. Grade 4: Death.

Table 1. Characteristics of foodborne diseases related to flesh foods in Morocco during 2010-2016

\begin{tabular}{|c|c|c|c|c|c|c|}
\hline Items & & Cases $*(\%)$ & Hospitalization* & Healing* & Death* & P-value \\
\hline \multirow{8}{*}{ Age groups } & Newborns (<4weeks) & $15(0.50)$ & 0 & 12 & 0 & \multirow{8}{*}{$<0.001$} \\
\hline & Nursling (4weeks- 12 moth) & $5(0.16)$ & 1 & 2 & 0 & \\
\hline & Toddlers (1-4 years) & $64(2.16)$ & 17 & 51 & 0 & \\
\hline & Children (5-14 years) & $428(14.44)$ & 51 & 392 & 1 & \\
\hline & Adolescents (15-19 years) & $194(6.54)$ & 30 & 914 & 1 & \\
\hline & Adults (20-74 years) & $1002(33.81)$ & 105 & 849 & 1 & \\
\hline & Elderly (>74 years) & $7(0.23)$ & 1 & 4 & 1 & \\
\hline & Unknown & $1248(42.1)$ & 16 & 369 & 0 & \\
\hline \multirow{3}{*}{ Sex } & Female & $944(31.85)$ & 167 & 765 & 1 & \multirow{3}{*}{$<0.001$} \\
\hline & Male & $1624(54.80)$ & 170 & 1463 & 3 & \\
\hline & Unknown & $395(13.33)$ & 7 & 365 & 0 & \\
\hline \multirow{3}{*}{ Type of diseases } & Collective & $2497(84.27)$ & 312 & 2322 & 4 & \multirow{3}{*}{$<0.001$} \\
\hline & Isolated & $455(15.35)$ & 30 & 261 & 0 & \\
\hline & Unknown & $11(0.37)$ & 2 & 10 & 0 & \\
\hline \multirow{5}{*}{ Season } & Autumn & $271(9.14)$ & 66 & 228 & 1 & \multirow{5}{*}{$<0.001$} \\
\hline & Winter & $185(6.24)$ & 12 & 158 & 1 & \\
\hline & Spring & $548(18.49)$ & 50 & 527 & 0 & \\
\hline & Summer & $430(14.51)$ & 32 & 412 & 0 & \\
\hline & Unknown & $1529(51.60)$ & 184 & 1268 & 2 & \\
\hline
\end{tabular}

*Number of cases

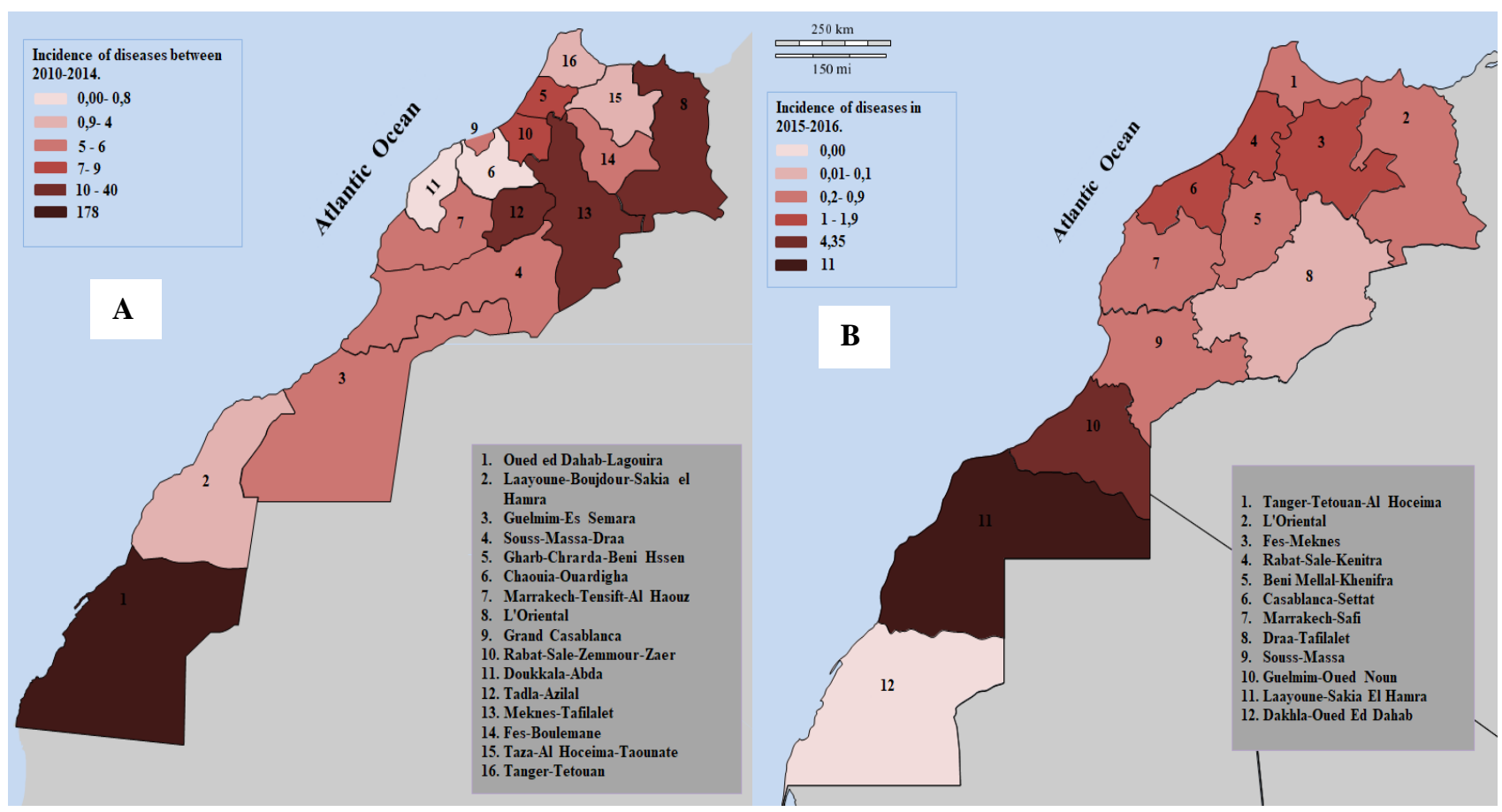

Figure 4. Incidence rates of foodborne diseases related to flesh foods by Moroccan regions during 2010-2014 (A) and during 2015-2016 (B) 
Table 2. Evolution, incidence and fatality rate of diseases in Morocco according to year and responsible flesh food

\begin{tabular}{|c|c|c|c|c|c|c|}
\hline Items & Cases* & Hospitalization* & Healing* & Death* & $\begin{array}{c}\text { Incidence } \\
\text { (per 100000) }\end{array}$ & $\begin{array}{c}\text { Fatality rate } \\
(\%)\end{array}$ \\
\hline \multicolumn{7}{|l|}{ Years } \\
\hline 2010 & 173 & 48 & 142 & 0 & 0.54 & 0 \\
\hline 2011 & 330 & 68 & 309 & 0 & 1.02 & 0 \\
\hline 2012 & 276 & 37 & 215 & 1 & 0.84 & 0.36 \\
\hline 2013 & 615 & 14 & 597 & 1 & 1.86 & 0.16 \\
\hline 2014 & 458 & 113 & 418 & 1 & 1.35 & 0.21 \\
\hline 2015 & 736 & 33 & 636 & 1 & 2.15 & 0.13 \\
\hline 2016 & 375 & 31 & 276 & 0 & 1.08 & 0 \\
\hline \multicolumn{7}{|l|}{ Flesh foods } \\
\hline Chicken & 226 & 48 & 179 & 0 & 0,68 & 0 \\
\hline Chicken skewers & 1177 & 86 & 1101 & 1 & 3,55 & 0.08 \\
\hline Turkey & 51 & 0 & 47 & 0 & 0,15 & 0 \\
\hline Turkey skewers & 61 & 0 & 57 & 0 & 0,18 & 0 \\
\hline Red Meat & 201 & 1 & 143 & 0 & 0,61 & 0 \\
\hline Minced red meat & 290 & 59 & 241 & 1 & 0,87 & 0.34 \\
\hline Giblets & 30 & 13 & 27 & 1 & 0,09 & 3.33 \\
\hline Delicatessen & 10 & 0 & 7 & 0 & 0,03 & 0 \\
\hline Fresh Aquatic products & 680 & 94 & 556 & 1 & 2,05 & 0.14 \\
\hline Frozen fish & 1 & 0 & 1 & 0 & 0,00 & 0 \\
\hline Canned fish & 234 & 4 & 233 & 0 & 0,71 & 0 \\
\hline Sushi & 2 & 0 & 1 & 0 & 0,01 & 0 \\
\hline \multicolumn{7}{|l|}{ Place } \\
\hline Home & 944 & 165 & 710 & 2 & 2,82 & 0.21 \\
\hline Restaurants & 614 & 12 & 713 & 1 & 1,83 & 0.16 \\
\hline Educational institutions & 557 & 27 & 469 & 0 & 1,66 & 0 \\
\hline Public & 494 & 29 & 463 & 1 & 1,47 & 0.20 \\
\hline Work place & 58 & 0 & 54 & 0 & 0,17 & 0 \\
\hline Unknown & 296 & 88 & 207 & 0 & 0,88 & 0 \\
\hline
\end{tabular}

*Number of cases

\section{DISCUSSION}

During 2010-2016, 17076 cases of foodborne diseases were detected in Morocco in which 2963 (17.35\%) were associated to flesh foods. The majority of cases were occurred in urban areas with a rate of $67.06 \%$ because of the overcrowding in urban middle which represents $59.54 \%$ of the Moroccan population during the study period (HCP), the availability of restaurants, work and study institutes representing $41.47 \%$ of cases and also the proximity to health facilities. The average age of affected population was $25 \pm 15.37$ years, adults represents the age group seriously affected by this problem $(33.81 \%)$, followed by children $(14.44 \%)$, and adolescents $(6.54 \%)$. Adults and children are the age groups most often affected by foodborne diseases in Morocco (Talbi et al., 2006; MAPPC, 2015). In the world, 96000 children die every year because of the foodborne diarrheal diseases that are responsible for more than the half of the global food borne disease cases, and related mainly to meat consumption (WHO, 2018). Men were the most affected with $54.80 \%$ in which $45.13 \%$ are contracted in public places and restaurants, this can be explained on the one hand by the change of eating habits in Morocco whereas the consumption out of home (fast food) becomes very common mainly for young between 25- 40 years, and in the other hand by the sociological changes allowing the development of women's work (Ouazzani, 2018; Allali, 2017). The majority of cases were collective $(84.27 \%$ ) because of the consumption in group or of the same meals. Chicken as the most accessible meat in Morocco (Sarter, 2004) was the major involved flesh product in diseases cases $(47.35 \%)$. In USA, chicken is the most responsible for poultry-associated outbreaks (64\%) (Chai et al., 2017).

The second leading cause of foodborne diseases related to flesh foods in Morocco during the period of study is attributed to fish and aquatic products (30.94\%). However, even though Morocco is considered as one of the major producer countries of marine captures worldwide, whereas it was classified as the 17th producing country in 2014 and the 13th in 2016 (FAO, 2016; FAO, 2018), the consumption of fish by Moroccans is low compared to other types of meat (ITC, 2015). Apart chemicals toxics mainly histamine and mercury that are known as the major toxins causing foodborne diseases related to fish consumption (Colombo et al., 2018; WHO, 2007) and which have been detected in low levels in fish in Morocco (El Hariri et al., 2017; MAPPC, 2017). These economic and health damages are due to the lack of respect for the hygiene standards during the transport and marketing stages in non-refrigerated holds by artisanal fishermen (which insures the largest part of maritime products in the Moroccan market), what causes deterioration of hygienic and organoleptic quality of products even before arriving at the port (DSFF, 2008).

Concerning diseases related to the red meat consumption, cattle, sheep, goats and camels are the types mainly produced in Morocco (MAPMDREF, 2015). In this study, they were responsible for 491 (16.57\%) cases. The microbial quality of meat depends on the slaughter conditions, chilling temperatures during the slaughter and transportation process (Gram et al., 2002), while in Morocco, there is just six red meat's slaughterhouses recognized by the National Food Health Safety Product Office (ONSSA, 2017). 
The high fatality rate observed in this study was associated with giblets (3.33\%). Edible viscera including internal organ (liver, kidneys, thymus, heart and gizzard), and entrails (intestines) of a butcher animal are very popular, mainly poultry giblets (internal organs) because poultry is the most common consuming in Morocco (420000 tons/year) (HCP, 2016), however $92 \%$ of poultry meat and giblets produced by illegal slaughterhouses where the bright chicken, fresh meat and giblets are cohabited (AgriMaroc, 2017). The intestines of cattle, sheep, and goats are also largely used to make sausages using the traditional method in general, as a consequence, in Meknes city (Morocco), 80.77\% of analyzed sausages were unfit for consumption, and $21.79 \%$ were showed the presence of Salmonella (Ed-Dra, 2017).

In USA, during 1998-2008, 13405 foodborne disease outbreaks were registered by the centers for disease control and prevention (CDC), in which the most responsible foods were poultry (18.9\%), fish (18.6\%) and beef (11.9\%). Moreover, Clostridium perfringens and Salmonella were the most responsible pathogenic bacteria for illnesses caused by these foods (Gould, 2013).

Regarding the seasonal effect on the frequency of declared diseases, among $48.4 \%$ of recorded cases during the four seasons, $38.21 \%$ were detected in spring, $29.98 \%$ in summer, $18.89 \%$ in autumn and just $12.90 \%$ in winter, which indicate that the increase of temperature during spring and summer seasons has a very important role in the flesh foods spoilage, because of the availability of humidity and the optimum temperature for the multiplication of the majority of foodborne bacteria (Al-Jasass, 2013). This result is confirmed by the study that was conducted in Meknes city (Morocco), and which shows the important impact of the seasonal variation on the retail beef meat's hygienic quality (Boukili, 2019). The degree of severity for the larger part of cases was considered moderate during all seasons (81.77\%), however it was severe during spring and summer respectively in $9.12 \%$ and $2.79 \%$ of cases.

According to the MAPPC, since 1980, foodstuffs in general are among the first three responsible agents for poisoning in Morocco. During 1999-2008, they were considered as the first cause of poisoning (13638 cases), which constitutes a worrying health problem.

\section{CONCLUSION}

The frequency of foodborne diseases reported by the MAPPC is increasing which indicates that the center provides more effort to better assess the situation. However, foodborne diseases recorded in the region of Oued ed Dahab-Lagouira during 2010-2014 were not declared to the MAPPC until the year 2015, 306 cases corresponding to this region were declared by the press media. Moreover, during the two last years of this study, the MAPPC has not received any cases from the region of Dakhla- Oued Eddahab (same location), which indicate that the responsible for health must provide more effort at this level. Furthermore, the responsible institutes for food safety in Morocco must also ensure more certified slaughterhouses, and establish monitoring and control systems to manage the artisanal fishing sector.

\section{DECLARATIONS}

\section{Acknowledgments}

The authors would like to gratefully acknowledge the Moroccan Anti-Poison and Pharmacovigilance Center, also the participants are acknowledged for their contribution to this study.

\section{Competing interests}

We have no conflict of interest to declare.

\section{Consent to publish}

The Moroccan Anti-Poison and Pharmacovigilance Center and all authors consent the publication of the article.

\section{Authors' contributions}

All the authors contributed to the writing and revision of the article.

\section{REFERENCES}

Allali F (2017). Evolution of food practices in Morocco. International Journal of Medicine and Surgery, 4: 70-73. DOI: dx.doi.org/10.15342\%2Fijms.v4is.145

Agri Maroc (2017). Non-compliance with sanitary standards in poultry slaughterhouses. Available at http://www.agrimaroc. $\mathrm{ma} /$ viande-volaille-normes-sanitaires/

Al-Jasass FM (2013). Assessment of the microbial growth and chemical changes in beef and lamb meat collected from supermarket and shop during summer and winter season. Research Journal of Recent Sciences, 2(4): 20-27.

Boukili M, Filali RF, Aboulkacem A, Sefiani M (2019). Assessment of factors influencing the hygienic quality of retail beef meat in Meknes City, Morocco. International Journal of Veterinary Science, 8(1): 43-48.

Chai SJ, Cole D, Nisler A and Mahon BE (2017). Poultry: The most common food in outbreaks with known pathogens, United States, 1998-2012. Epidemiology and Infection, 145(2): 316-25. DOI:10.1017/ S0950268816002375. 
Colombo FM, Cattaneo P, Confalonieri E and Bernardi C (2018). Histamine food poisonings: A systematic review and meta-analysis. Critical reviews in food science and nutrition, 58(7):1131-51. DOI:10.1080/10408398. 2016.1242476.

Dewey-Mattia D, Manikonda K, Hall AJ, Wise ME, Crowe SJ (2018). Surveillance for Foodborne Disease Outbreaks - United States, 2009-2015. Mobidity and Mortality weekly report surveillance summaries, 67(10):1-11. DOI:10.15585/mmwr.ss6710a1.

Directorate of Studies and Financial Forecasting (DSFF) (2008). Analysis of the fisheries and aquacultural sector in the new context. Ministry of Finance and Privatization, Morocco, pp. 1-47. http://www.abhatoo.net.ma/maalama-textuelle/developpementeconomique-et-social/developpement-economique/peche/aquaculture/analyse-du-secteur-des-peches-et-de-l-aquaculture-dansle-nouveau-contexte-synthese

El Hariri O, Bouchriti N and Bengueddour R (2017). Occurrence and Evaluation of the Risk of Histamine in Fish Products Marketed on the Moroccan Market. European Scientific Journal, 13(27). DOI: 10.19044/esj. 2017. v13n27p225

Ed-Dra A, Rhazi Filali F, El Allaoui A and Aboulkacem A (2017). Factors influencing the bacteriological quality of sausages sold in Meknes city, Morocco. International Food Research Journal, 24(3): 933-938.

Food and Agriculture Organization of the United Nations (FAO) (2013). Consumption of Fish and Fishery Products.

Food and Agriculture Organization of the United Nations (FAO) (2016). The state of world fisheries and aquaculture 2016. Rome, pp. 1-224. DOI: 10.18356/e68e16bb-en.

Food and Agriculture Organization of the United Nations (FAO) (2018). The state of world fisheries and aquaculture,. Rome, pp. 1227. DOI: $10.18356 / 8$ d6ea4b6-en.

Gould LH, Walsh KA, Vieira AR, Herman K, Williams IT, Hall AJ and Cole D (2013). Surveillance for foodborne disease outbreaks-United States, 1998-2008. Morbidity and Mortality Weekly Report: Surveillance Summaries, 62(2):1-34.

Gram L, Ravn L, Rasch M, Bruhn JB, Christensen AB and Givskov M (2002). Food spoilage-interactions between food spoilage bacteria. International journal of food microbiology, 78(1-2): 79-97. DOI: 10.1016/ s0168-1605(02)00233-7.

Heredia N and García S (2018). Animals as sources of food-borne pathogens: A review. Animal Nutrition, 4-9. DOI: 10.1016/j.aninu.2018.04.006.

High Commission for Planning (HCP) (2010-2016). Morocco in figures. Morocco.

High Commission for Planning (HCP) (2016). Presentation of the results of the National Household Consumption and Expenditure Survey of 2013/2014. Morocco, pp. 1-18.

International trade center (ITC) (2015). Seafood sector EDEC Morocco. Geneva, Switzerland, pp. 1-209.

Mead PS, Slutsker L, Dietz V, McCaig LF, Bresee JS, Shapiro C, Griffin PM and Tauxe RV (1999). Food-related illness and death in the United States. Emerging infectious diseases, 5(5):607. DOI: 10.3201/ eid0505.990502

Ministry of agriculture, Fisheries, Rural Development, water and Forests (MAPMDREF) (2015). Moroccan agriculture in Figures 2014. Morocco, pp. 1- 17.

Ministry of agriculture, Fisheries, Rural Development, water and Forests (MAPMDREF) (2017). Moroccan agriculture in Figures 2016. Morocco, pp. 1-29.

National Institute for Health Surveillance (Invs) (2014). Surveillance of collective food poisoning, Mandatory reporting data. Public health, France, pp.1-11.

National Institute for Health Surveillance (Invs) (2015). Surveillance of collective food poisoning, Mandatory reporting data. Public health, France, pp.1-11

National Food Health Safety Product Office (ONSSA) (2017). List of establishments for the preparation of approved meat and meat products. Morocco, pp 1-21.

Nohr D and Biesalski HK (2007). 'Mealthy'food: meat as a healthy and valuable source of micronutrients. Animal, 1(2):309-16. DOI: $10.1017 / \mathrm{s} 1751731107657796$.

Novoslavskij A, Terentjeva M, Eizenberga I, Valciņa O, Bartkevičs V and Bērziņš A (2016). Major foodborne pathogens in fish and fish products: a review. Annals of microbiology, 66(1):1-5. DOI: 10.1007/s13213-015-1102-5.

Omer MK, Álvarez-Ordoñez A, Prieto M, Skjerve E, Asehun T and Alvseike OA (2018). A Systematic Review of Bacterial Foodborne Outbreaks Related to Red Meat and Meat Products. Foodborne pathogens and disease, 15 (10): 598-611. DOI: 10.1089/fpd.2017.2393.

Ouazzani I (2018). Moroccan consumers prefer fast food delivery. Morocco. https://www.huffpostmaghreb.com /entry/lesconsommateurs-marocains-preferent-se-faire-livrer-des-fast-food-selon-une-etude_mg_5ae3315 0e4b02baed1b9c95b

Persson HE, Sjöberg GK, Haines JA and Garbino JP (1998). Poisoning severity scores. Grading of acute poisoning. Journal of Toxicology: Clinical Toxicology, 36 (3): 205-213. DOI: 10.3109/15563659809028940.

Poison control and pharmacovigilance center of Morocco (MAPPC) (2009). Official publications of the poison center of Morocco. Ministry of health, Morocco, pp. 1-16.

Poison control and pharmacovigilance center of Morocco (MAPPC) (2010). Foodborne diseases, Official publications of the poison center of Morocco. Ministry of health, Morocco, pp. 1-16.

Poison control and pharmacovigilance center of Morocco (MAPPC) (2015). Official publications of the poison center of Morocco. Ministry of health, Morocco, pp.1-16.

Poison control and pharmacovigilance center of Morocco (MAPPC) (2017). Official publications of the poison center of Morocco, Mercury exposure in Morocco. Ministry of health, Morocco, pp. 1-16.

Ritchie H and Roser M (2017). Meat and Seafood Production and Consumption. Our World In Data.

Society for applied microbiology (SfAM) (2014). Poultry as a reservoir for foodborne disease: news and features. 
Sarter G (2004). Between beldi and roumi: preferences of urban consumers and production of chickens in Morocco. Cahiers Agricultures, 13(1):75-78.

Talbi M, Bencheikh RS, Mokhtari A and Soulaymani A (2006). The study of food poisoning in Morocco. The 1st National Congress of the Improvement of Agricultural Production, Morocco.

World Cancer Research Fund (WCRF) (2018). Meat, Fish and Dairy Products and the Risk of Cancer. London, pp. 1-11.

World Health Organization (WHO) (2018). Salmonella (non-typhoidal).

World Health Organization (WHO) (2000). INTOX Definitions.

World Health Organization (WHO) (2018). WHO's first ever global estimates of foodborne diseases find children under 5 account for almost one third of deaths.

World Health Organization (2007). Exposure to mercury: a major public health concern. Geneva, Switzerland, pp.1-4. 